\title{
The role of proteinuria, paricalcitol and vitamin D in the development of post-transplant diabetes mellitus
}

\author{
Dedinska $\mathrm{I}^{1}$, Laca $\mathrm{L}^{1}$, Miklusica $\mathrm{J}^{1}$, Palkoci $\mathrm{B}^{1}$, Skalova $\mathrm{P}^{1}$, Kantarova $\mathrm{D}^{2}$, Galajda $\mathrm{P}^{2}$, Mokan $\mathrm{M}^{2}$ \\ Department of Surgery and Transplantation Center, University Hospital Martin and Jessenius Medical \\ Faculty of Comenius University, Martin, Slovakia. idedinska@yahoo.co.uk
}

\section{ABSTRACT}

INTRODUCTION: Post-transplant diabetes mellitus (PTDM) occurs most frequently during the first year after transplantation. We focused on parameters of calcium-phosphate metabolism and proteinuria as possible new risk factors for PTDM after kidney transplantation.

MATERIALS AND METHODS: We have prospectively identified risk factors for post-transplant diabetes mellitus with follow-up of 12 months in a set of 167 patients after kidney transplantation. Patients with diabetes mellitus type 1 and type 2 as well as patients using ciclosporin A or mTOR inhibitor have been excluded from the monitoring. From the perspective of immunosuppression it was a homogeneous set of patients.

RESULTS: We identified the following independent risk factors for PTDM in our set: average proteinuria $>0.300$ $\mathrm{g} / 24 \mathrm{~h}$ (HR 3.0785, (95\% Cl 1.6946-5.5927), p=0.0002), level of vitamin $\mathrm{D}<20 \mathrm{ng} / \mathrm{ml}(\mathrm{HR} 5.4517,(95 \% \mathrm{Cl}$ 2.3167-11.8209), $\mathrm{p}<0.0001)$ baseline serum level of phosphorus $>1.45 \mathrm{mmol} / \mathrm{l}(\mathrm{HR} 0.0821$, $(95 \% \mathrm{Cl0.0042-}$ 1.5920), $p=0.0439)$. The lowest occurrence of PTDM and proteinuria was recorded in patients whose treatment included paricalcitol $(p<0.0001)$ and these patients had at the same time the highest level of vitamin $D(p<0.0001)$. CONCLUSION: Deficit of vitamin D, proteinuria and hyperphosphatemia have been independent risk factors for the development of PTDM in our set. We identified the usage of paricalcitol as protective factor with regard to the PTDM development (Tab. 6, Fig. 4, Ref. 29). Text in PDF www.elis.sk. KEYWORDS: post-transplant diabetes mellitus, proteinuria, vitamin D, paricalcitol, kidney transplantation.

\begin{abstract}
Abbreviations: PTDM - post-transplant diabetes mellitus, oGTT - oral glucose tolerance test, CKD - chronic kidney disease, HPTH - hyperparathyreosis, PTH - parathormone, KT - kidney transplantation, ADA - American diabetes association, DM2 - diabetes mellitus type 2, APKD - polycystic kidney disease, CKDMBD - bone disease, BMI - body mass index, HbA1c - glycated hemoglobin, ACEI - angiotensin-converting-enzyme inhibitors
\end{abstract}

\section{Introduction}

Diabetes mellitus after transplantation is a serious and frequently occurring metabolic complication and both the name and the definition have developed during the last fifty years. The posttransplant diabetes mellitus (PTDM) occurs most frequently during the first year after transplantation and does not affect the patient and graft survival (and even the function of the graft) during the first years after the transplantation in any significant way. However, this difference becomes significant in a long-term horizon

${ }^{1}$ Department of Surgery and Transplantation Center, University Hospital Martin and Jessenius Medical Faculty of Comenius University, Martin, Slovakia, and ${ }^{2}$ Ist Department of Internal Diseases, University Hospital Martin and Jessenius Medical Faculty of Comenius University, Martin, Slovakia

Address for correspondence: I. Dedinska, MD, PhD, Department of Surgery and Transplantation Center, University Hospital Martin, Kollarova 2, SK-036 01 Martin, Slovakia.

Phone: +421.43 .4203920$ from 7-10 years after the transplantation (1). Taking into account the improved quality of healthcare, advanced immunosuppressive protocols, surgery techniques and especially well-functioning donor programme, it is clear that numbers of transplanted patients will grow. Development of transplantation programme and development of new immunosuppressants improve the survival of both the graft and the patient after the transplantation, the risk of acute rejection is reduced, but the risk of other complications that affect especially the long-term survival of the patient, graft as well as the patient's quality of life, increases in the population of transplanted patients.

The graft survival is significantly affected from the long-term perspective by cardiovascular morbidity and mortality. We know at the present era of modern and effective immunosuppression that post-transplant diabetes mellitus is an independent predictor of cardiovascular events (2). Valderhaug et al followed 1410 consecutive kidney recipients transplanted between years 1995 and 2006 and examined the predictive value of an oral glucose tolerance test (oGTT) at 10 weeks. Patients in whom the oGTT demonstrated PTDM had a 1.8 fold increase in cardiovascular disease mortality and a 1.5-fold increase in overall mortality (3).

We have proven in the already published analysis of risk factors for PTDM in a homogeneous set of patients from the perspective of immunosuppression that the age at the time of transplantation, positive family anamnesis for diabetes mellitus type 2 , body mass index at the time of transplantation more than $30 \mathrm{~kg} / \mathrm{m}^{2}$, predia- 


\section{1-407}

betes before transplantation and proteinuria $>0.15 \mathrm{~g} /$ day are independent risk factors for PTDM development (follow-up - 12 months) (4). We have therefore focused in the said set of patients on proteinuria and parameters of calcium-phosphate metabolism including the level of vitamin D, which could be identified as further risk factors for the PTDM.

Vitamin D deficiency has been associated with poor outcomes in the general population and in CKD (chronic kidney disease) patients $(5,6,7)$. An univocal definition of $25(\mathrm{OH}) \mathrm{D}$ deficiency is still lacking, as no randomized controlled trials (RCTs) have yet been designed to investigate the best $25(\mathrm{OH}) \mathrm{D}$ targets to improve hard endpoints in humans. In the general population, serum $25(\mathrm{OH}) \mathrm{D}$ levels $<20 \mathrm{ng} / \mathrm{ml}$ are considered deficient, 20-29.9 ng/ml insufficient, and levels $\geq 30 \mathrm{ng} / \mathrm{ml}$ sufficient $(8,9)$. Optimal vitamin D levels may vary according to the specific disease and outcome of interest. 25(OH)D levels $>10 \mathrm{ng} / \mathrm{ml}$ were shown to be adequate to prevent rickets and osteomalacia, whereas $25(\mathrm{OH}) \mathrm{D}$ levels $>30$ $\mathrm{ng} / \mathrm{ml}$ may be required to prevent secondary hyperparathyreosis (HPTH) or osteoporosis (10).

Proteinuria is a common problem occurring in up to $45 \%$ of renal transplant recipients. Proteinuria is associated with worse clinical outcomes including an increased risk of death, cardiovascular events, and graft loss (11).

We determined through a thorough analysis of the set that proteinuria in our set can be significantly linked with the usage of paricalcitol. Paricalcitol, a selective vitamin D receptor activator, is indicated in the prevention and treatment of secondary hyperparathyroidism. Several analyses (however, only in small sets of patients) confirmed that paricalcitol in patients after kidney transplantation reduces the values of parathormone (PTH), has a positive effect on proteinuria, and is easily tolerated. When compared with any other analogs, paricalcitol causes less significant hypercalcemia and hyperphosphatemia, which is related to the lower effect on the transport proteins for calcium and phosphorus in the bowels (12). There is little information on the use of paricalcitol in patients after renal transplantation.

\section{Material and methods}

We have been prospectively evaluating selected risk factors for PTDM in the set of 167 patients (Europids) after primary kidney transplantation (KT) from a dead donor in Transplant center Martin. PTDM was diagnosed according to the ADA (American diabetes association) criteria, oral glucose tolerance test (oGTT) was realised in the 10th - 12th week after transplantation and in the 12 th month after transplantation.

We determined in the already published study for all patients the age at the time of transplantation, sex, family history of diabetes mellitus type 2 (DM2) - parents, siblings, grandparents, compatibility index and number of HLA-mismatches, presence of risk HLAs (A30, B27, B42), basic diagnosis of kidney failure (we have differentiated patients with polycystic kidney disease APKD). Monitored parameters were completed in this analysis with the examination of serum concentration of calcium, phosphorus, intact parathormone (iPTH) and levels of vitamin D. Values of

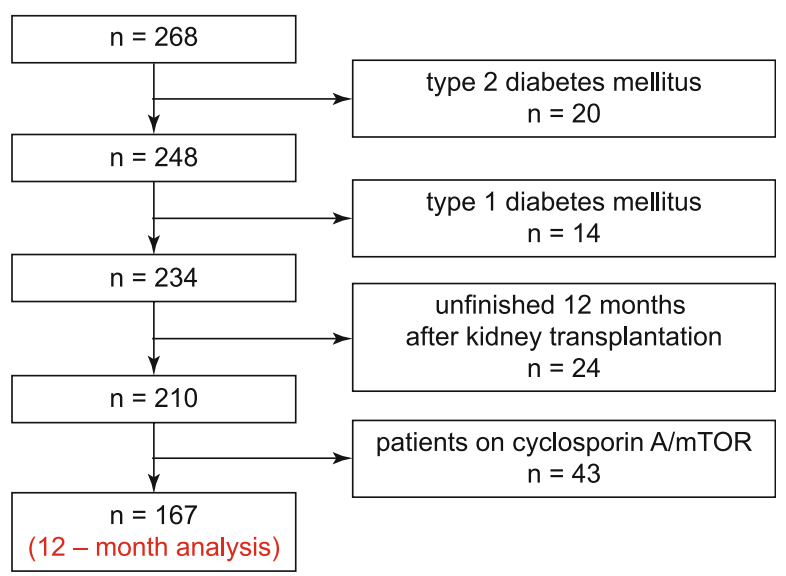

Fig. 1. Inclusion criteria.

vitamin D and iPTH were determined before the transplantation and subsequently in 3rd, 6th and 12th month after the transplantation. Proteinuria, serum value of calcium, phosphate and level of tacrolimus were determined during each check-up in the transplant centre (at average 22 times during the monitored period).

We further focused on the treatment of bone disease (CKDMBD): cinalacet, cholecalciferol, paricalcitol or none (or combined treatment) before the transplantation, 6 months after the transplantation and 12 months after the transplantation. We have found the influence of CKD-MBD treatment on the development of PTDM in the monitored period 12 months after the transplantation.

Only patients using tacrolimus in immunosuppressive mode were included in the monitoring (Fig. 1) and patients with diabetes mellitus type 1 or type 2 diagnosed before the transplantation were excluded from the monitoring.

We used a certified statistical program MedCalc version 13.1.2. (MedCalc Software's VAT registration number is BE 0809344640 , Member of International Association of Statistical Computing, Ostend, Belgium) for statistical evaluation and we used following statistical analyses: Student's t-test, chi-square test, Cox proportional hazard model. We consider the value $\mathrm{p}<0.05$ to be statistically significant.

\section{Ethical approval}

All procedures performed in studies involving human participants are approved with the ethical standards of the institutional and/or national research committee and with the 1964 Helsinki declaration and its later amendments or comparable ethical standards.

\section{Results}

There were 167 patients in this set of patients, out of which $103(61.7 \%)$ patients formed the control set and 64 (38.3\%) patients formed the set with PTDM diagnosed in monitored period (12 months after primary kidney transplantation). Basic set characteristics are shown in Table 2. 
Tab. 1. Comparison of control set vs. PTDM set in terms of immunosuppression (12 months after transplantation).

\begin{tabular}{lccc}
\hline 12-month analysis & $\begin{array}{c}\text { control set } \\
\mathrm{n}=103\end{array}$ & $\begin{array}{c}\text { PTDM set } \\
\mathrm{n}=64\end{array}$ & $\mathrm{p}$ \\
\hline average level of TAC $(\mathrm{ng} / \mathrm{ml})$ & $4.7 \pm 0.9$ & $4.8 \pm 1.2$ & 0.5592 \\
\hline average dose of prednisone/day $(\mathrm{mg})$ & $8.2 \pm 2.3$ & $8.8 \pm 2.0$ & 0.0877 \\
\hline average dose of MMF/day $(\mathrm{mg})$ & $849.4 \pm 264.2$ & $911.7 \pm 175.4$ & 0.0919 \\
\hline average dose of mycophenolate sodium/day $(\mathrm{mg})$ & $670.7 \pm 292$ & $721.9 \pm 113$ & 0.1734 \\
\hline
\end{tabular}

TAC - tacrolimus, MMF - mycophenolate mofetil

Tab. 2. Patients characteristics.

\begin{tabular}{|c|c|c|c|}
\hline & $\begin{array}{c}\text { control set } \\
n=103\end{array}$ & $\begin{array}{c}\text { PTDM set } \\
\mathrm{n}=64\end{array}$ & $\mathrm{p}$ \\
\hline age at the time of transplantation (years) & $43 \pm 12.1$ & $50.5 \pm 9.6$ & $<0.0001$ \\
\hline dialysis before transplantation (months) & $34.1 \pm 19.2$ & $37.3 \pm 14.9$ & 0.2572 \\
\hline positive family history of DM2 (\%) & 29.8 & 78.1 & $<0.0001$ \\
\hline male sex $(\%)$ & 62.1 & 59.4 & 0.8627 \\
\hline HLA A30 (\%) & 2.9 & 0 & 0.4375 \\
\hline HLA B27 (\%) & 9.6 & 10.9 & 0.9937 \\
\hline HLA B42 (\%) & 1 & 0 & 0.8335 \\
\hline average number of HLA mismatches & $3.5 \pm 1.2$ & $3.7 \pm 1.4$ & 0.3266 \\
\hline APKD (\%) & 10.4 & 17.2 & 0.2839 \\
\hline ECD donor $(\%)$ & 17.3 & 21.9 & 0.5926 \\
\hline treatment with methylprednisolone $(\mathrm{g})$ - induction & 1000 & 1000 & 1.0000 \\
\hline pulse treatment with methylprednisolone (\%) except for induction & 36.4 & 34.9 & 0.9792 \\
\hline average dose $(\mathrm{g})$ except for induction & $2.0 \pm 0.7$ & $2.3 \pm 0.7$ & 0.0086 \\
\hline BMI at the time of transplantation $\left(\mathrm{kg} / \mathrm{m}^{2}\right)$ & $24.9 \pm 4.1$ & $26.5 \pm 4.3$ & 0.0170 \\
\hline weight at the time of transplantation $(\mathrm{kg})$ & $73.7 \pm 15.1$ & $78.3 \pm 14.5$ & 0.0533 \\
\hline BMI 12 months after transplantation $\left(\mathrm{kg} / \mathrm{m}^{2}\right)$ & $26.8 \pm 5.3$ & $28.5 \pm 4.1$ & 0.0318 \\
\hline weight 12 months after transplantation $(\mathrm{kg})$ & $78.5 \pm 15.6$ & $83.5 \pm 13.1$ & 0.0361 \\
\hline weight gain 12 months after transplantation $(\mathrm{kg})$ & $5.6 \pm 5.1$ & $6.2 \pm 5.6$ & 0.4834 \\
\hline average level of TAG $(\mathrm{mmol} / \mathrm{l})$ & $2.0 \pm 0.7$ & $1.9 \pm 0.5$ & 0.3262 \\
\hline average level of cholesterol (mmol/1) & $4.4 \pm 0.7$ & $4.5 \pm 0.5$ & 0.3262 \\
\hline artery hypertension (\%) & 96.2 & 98.4 & 0.7277 \\
\hline basiliximab in induction (\%) & 52.4 & 84.4 & 0.0001 \\
\hline average level of magnesemia $(\mathrm{mmol} / \mathrm{l})$ & $0.79 \pm 0.1$ & $0.78 \pm 1.3$ & 0.9393 \\
\hline prediabetes before transplantation (\%) & 0 & 15.6 & 0.0001 \\
\hline HCV PCR positivity (\%) & 0.9 & 4.7 & 0.2914 \\
\hline CMV replication (\%) & 45.8 & 45.2 & 0.9286 \\
\hline average number of copies (cop/ml) & 3500 & 3800 & 0.9763 \\
\hline average proteinuria $(\mathrm{g} / 24 \mathrm{~h})$ & $0.18 \pm 0.13$ & $0.23 \pm 0.16$ & 0.0308 \\
\hline
\end{tabular}

DM2 - diabetes mellitus type 2, APKD - polycystic kidney disease, ECD - expanded criteria donor, BMI - body mass index, TAG - triacylglycerols, HCV - hepatitis C, $\mathrm{CMV}$ - cytomegalovirus, prediabetes - impaired glucose tolerance, impaired fasting glucose

Average level of tacrolimus (during the 12 monitored months after kidney transplantation) was without statistically significant difference in both sets $(p=0.5592)$, similarly the average dose of prednisone/day $(p=0.0877)$. Average level of mycophenolate mofetil/day (or mycophenolate sodium) was also without statistically significant difference between the monitored sets $(\mathrm{p}=$ 0.0919 - mycophenolate mofetil and $p=0.1734$ - mycophenolate sodium (Tab. 1). In view of the above, both sets were homogenous in terms of the administered immunosuppression and individual monitored parameters were not distorted by the administered immunosuppression (4).

Patients who developed PTDM during the monitored period were compared to patients in the control set significantly older, had significantly more frequently positive family history for diabetes mellitus type 2, higher value of body mass index (BMI) at the time of transplantation and 12 months after the transplantation, more frequent prediabetes before the transplantation (impaired glucose tolerance or impaired fasting glucose) and significantly higher value of proteinuria.

We subsequently added parameters of bone metabolism at the baseline at the time of transplantation, 6 and 12 months after the transplantation (Tabs 3, 4, 5).

Patients who developed PTDM during the monitored period had as compared to the control set significantly lower base line levels of vitamin D and higher levels of phosphorus in the serum. We identified in the set of patients with PTDM 6 months after the 
transplantation significantly lower levels of vitamin D as compared to the control set. We further determined that treatment of patients in the control set included cholecalciferol significantly more often as compared to patients with PTDM. Significantly lower levels of vitamin D in the set of patients with PTDM were determined also 12 months after the transplantation.

We found out that 62 patients had constantly (during each monitoring) value of vitamin D less than $30 \mathrm{ng} / \mathrm{ml}$.

We identified by means of multivariate analysis following independent risk factors for PTDM in our set: average proteinuria during the monitored period more than $0.300 \mathrm{~g} / 24$ hours, value

Tab. 3. Characteristics of the set after parameters of bone metabolism are added - base line.

\begin{tabular}{lccc}
\hline base line & $\begin{array}{c}\text { control set } \\
\mathrm{n}=103\end{array}$ & $\begin{array}{c}\text { PTDM } \\
\mathrm{n}=64\end{array}$ & $\mathrm{p}$ \\
\hline vitamin D $(\mathrm{ng} / \mathrm{ml})$ & $32.4 \pm 9.7$ & $23.1 \pm 7.6$ & 0.0282 \\
$\mathrm{iPTH}(\mathrm{pg} / \mathrm{ml})$ & $346.8 \pm 250.3$ & $211.2 \pm 182.2$ & 0.1830 \\
$\mathrm{Ca}(\mathrm{mmol} / \mathrm{l})$ & $2.2 \pm 0.2$ & $2.2 \pm 0.3$ & 1.000 \\
$\mathrm{P}(\mathrm{mmol} / \mathrm{l})$ & $1.2 \pm 0.9$ & $1.9 \pm 0.4$ & 0.0374 \\
cinacalcet $(\%)$ & 31.1 & 12.5 & 0.3262 \\
cholecalciferol $(\%)$ & 34 & 10.9 & 0.2276 \\
paricalcitol $(\%)$ & 78.6 & 35.9 & 0.0600 \\
\hline
\end{tabular}

Tab. 4. Characteristics of the set after parameters of bone metabolism are added $\mathbf{- 6}$ months after the transplantation.

\begin{tabular}{lccc}
\hline $\begin{array}{l}\text { 6M after } \\
\text { transplantation }\end{array}$ & $\begin{array}{c}\text { control set } \\
\mathrm{n}=103\end{array}$ & $\begin{array}{c}\text { PTDM } \\
\mathrm{n}=64\end{array}$ & $\mathrm{p}$ \\
\hline vitamin D $(\mathrm{ng} / \mathrm{ml})$ & $38.5 \pm 8.8$ & $22.7 \pm 10.9$ & 0.0022 \\
iPTH $(\mathrm{pg} / \mathrm{ml})$ & $202.5 \pm 153.8$ & $129.9 \pm 58,4$ & 0.1798 \\
$\mathrm{Ca}(\mathrm{mmol} / \mathrm{l})$ & $2.5 \pm 0.2$ & $2.4 \pm 0.1$ & 0.1744 \\
$\mathrm{P}(\mathrm{mmol} / \mathrm{l})$ & $0.8 \pm 0.2$ & $1.0 \pm 0.2$ & 0.0382 \\
cinacalcet $(\%)$ & 19.4 & 7.8 & 0.4648 \\
cholecalciferol $(\%)$ & 77.7 & 29.7 & 0.0359 \\
paricalcitol $(\%)$ & 29.1 & 10.9 & 0.3214 \\
\hline
\end{tabular}

Tab. 5. Characteristics of the set after parameters of bone metabolism are added $\mathbf{- 1 2}$ months after the transplantation.

\begin{tabular}{lccc}
\hline $\begin{array}{l}\text { 12M after } \\
\text { transplantation }\end{array}$ & $\begin{array}{c}\text { control set } \\
\mathrm{n}=103\end{array}$ & $\begin{array}{c}\text { PTDM } \\
\mathrm{n}=64\end{array}$ & $\mathrm{p}$ \\
\hline vitamin D $(\mathrm{ng} / \mathrm{ml})$ & $41.2 \pm 13.1$ & $23.5 \pm 9.6$ & 0.0029 \\
iPTH $(\mathrm{pg} / \mathrm{ml})$ & $113.9 \pm 81.7$ & $92.7 \pm 39.7$ & 0.4700 \\
$\mathrm{Ca}(\mathrm{mmol} / \mathrm{l})$ & $2.5 \pm 0.1$ & $2.5 \pm 0.2$ & 1.000 \\
$\mathrm{P}(\mathrm{mmol} / \mathrm{l})$ & $0.9 \pm 0.2$ & $1.0 \pm 0.2$ & 0.2783 \\
cinacalcet $(\%)$ & 21.4 & 3.1 & 0.2238 \\
cholecalciferol $(\%)$ & 78.6 & 46.9 & 0.1530 \\
paricalcitol $(\%)$ & 24.3 & 15.6 & 0.6352 \\
\hline
\end{tabular}

Tab. 6. Cox's regression Hazard model.

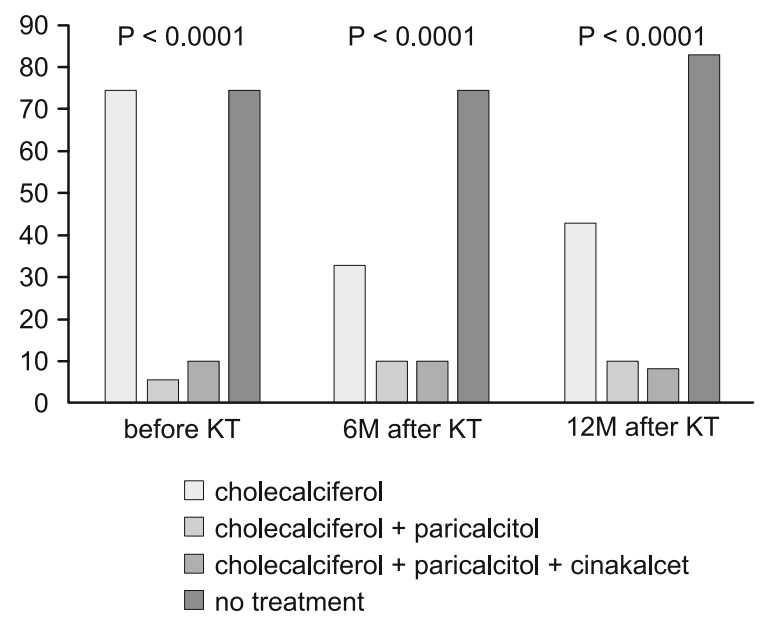

Fig. 2. Impact of the treatment type on the PTDM development - graph shows \% of patients with PTDM development.

of vitamin D less than $30 \mathrm{ng} / \mathrm{ml}$ (ng each monitoring) and serum value of phosphorus at the time of transplantation more than 1.45 mmol/1 (Tab. 6).

We learned by using the correlation coefficient that the occurrence of PTDM negatively correlates with the level of vitamin D - baseline ( $\mathrm{r}=-0.6210$ (95\% CI for $\mathrm{r}:-0.7886$ to -0.3674$), \mathrm{p}<$ 0.0001 ), what means that lower base line level of vitamin D increases the occurrence of PTDM in our set. We analogically applied the correlation coefficient also in the case of proteinuria and again confirmed that the occurrence of PTDM significantly rises with the average value of proteinuria $(r=0.3809(95 \% \mathrm{CI}$ for $\mathrm{r}$ : 0.2134 to $0.5266), p<0.0001)$. However, we did not confirm significantly higher occurrence of PTDM with higher value of phosphorus at the time of transplantation $(\mathrm{r}=0.01690,(95 \% \mathrm{CI}$ for $\mathrm{r}:-0.4536$ to 0.4800$), \mathrm{p}<0.9469$ ).

We further analyzed the impact of treatment of secondary hyperparathyroidism (cholecalciferol, cinacalcet and paricalcitol) on the PTDM development (Fig. 2). The average dose (i.e. during 12 monitored months after the transplantation) of cholecalciferol was $17 \pm 6$ drops/week, paricalcitol $2.8 \pm 1.8 \mu \mathrm{g} /$ week and cinacalcet $42.3 \pm 12 \mathrm{mg} /$ day. We learned that the highest occurrence of PTDM was in the set of patients who did not use any preparation in their treatment, or used only cholecalciferol in monotherapy, and that at the baseline, 6 months after the transplantation as well as 12 months

\begin{tabular}{|c|c|c|c|}
\hline & Hazard ratio & CI $95 \%$ & $\mathrm{p}$ \\
\hline proteinuria (average) $\geq 0.300 \mathrm{~g} / 24$ hours & 3.0785 & $1.6946-5.5927$ & 0.0002 \\
\hline vitamin $\mathrm{D}<20 \mathrm{ng} / \mathrm{ml}^{*}$ & 5.4517 & $2.3167-11.8209$ & $<0.0001$ \\
\hline vitamin D 21-30 ng/ml** & 1.3167 & $1.0057-1.8741$ & 0.0322 \\
\hline vitamin D 31-40 ng/ml & 1.1185 & $0.8955-1.2353$ & 0.0786 \\
\hline vitamin $\mathrm{D}>40 \mathrm{ng} / \mathrm{ml}$ & 0.4500 & $0.2552-1.6932$ & 0.6585 \\
\hline phosphorus at the time of transplantation $<0.81 \mathrm{mmol} / 1$ & 0.0565 & $3.4926-4.9317$ & 0.8364 \\
\hline phosphorus at the time of transplantation $0.81-1.45 \mathrm{mmol} / 1$ & 0.0366 & $1.7556-4.5512$ & 0.2192 \\
\hline phosphorus at the time of transplantation $>1.45 \mathrm{mmol} / 1$ & 0.0821 & $0.0042-1.5920$ & 0.0439 \\
\hline
\end{tabular}




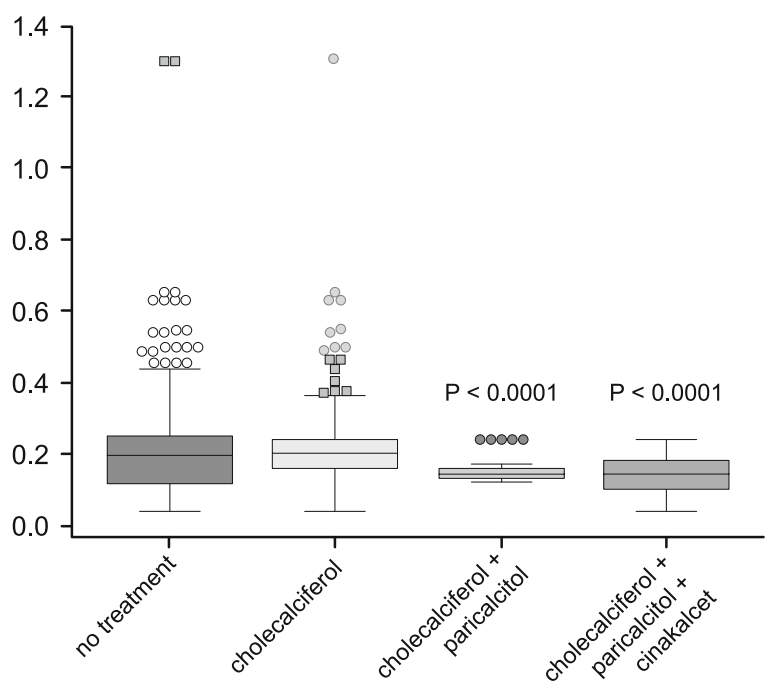

Fig. 3. Average value of proteinuria (g/day) according to treatment.

after the transplantation. On the other hand, the lowest incidence of PTDM was recorded in the set of patients whose treatment included (again at the base line, 6 months after the transplantation as well as 12 months after the transplantation) cholecalciferol + paricalcitol or cholecalciferol + paricalcitol + cinacalcet.

We similarly evaluated also the impact of treatment of the secondary hyperparathyroidism (cholecalciferol, cinacalcet and paricalcitol) on the average value of proteinuria during the monitored period (Fig. 3). The significantly lowest proteinuria was recorded for patients whose treatment included cholecalciferol and paricalcitol with or without cinacalcet.

Figure 4 shows average levels of vitamin D during the monitored period according to the treatment of secondary hyperparathyroidism. We learned that significantly highest levels of vitamin D had those patients who were treated with cholecalciferol and paricalcitol with or without cinacalcet or whose treatment included only cholecalciferol. Patients with no treatment had clearly lowest levels of vitamin D.

\section{Discussion}

The most important finding arising from our analysis is the fact that hypovitaminosis $\mathrm{D}$ is an independent risk factor for the development of PTDM. Vitamin D deficit is associated with higher occurrence of diabetes mellitus type 2 and it is also known that substitution treatment with vitamin $\mathrm{D}$ acts as a prevention of progression of prediabetes conditions to diabetes mellitus type 2 (8, 13). Vitamin D insufficiency is associated with increased glycated hemoglobin (HbA1c) levels and resistance to insulin $(14,15)$. Authors Tabesh et al described the impact of supplementing vitamin D and calcium on the reduction of serum level of interleukin 6 and tumor necrosis factor- $\alpha$ in patients with diabetes mellitus type 2 (16). Meta-analysis of authors George et al points out that supplementation with vitamin D improves values of fasting blood glucose and reduces insulin resistance, but does not affect the

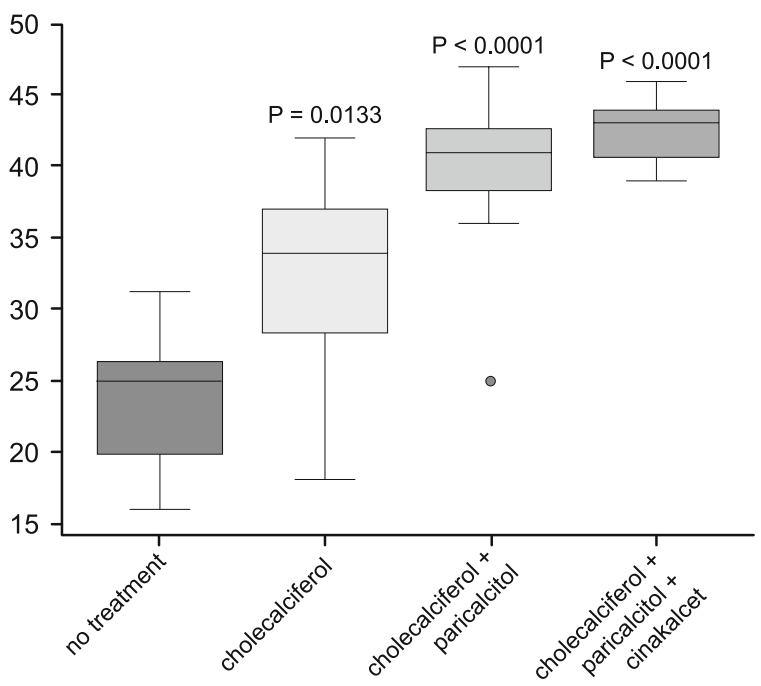

Fig. 4. Average level of vitamin $D(\mathrm{ng} / \mathrm{ml})$ according to treatment

value of glycosylated hemoglobin (HbA1c) (17). To the contrary, another meta-analysis did not confirm the effect of supplementation of vitamin D on the glucose metabolism. However, authors of this meta-analysis point out that results can be influenced by high heterogeneity of studies and short follow-up duration (18).

No randomized study has so far confirmed whether the vitamin D deficit is a risk factor for the PTDM development. The ongoing randomized controlled study VITALE with follow up of 12-48 months, which follows the effect of substitution treatment with calcitriol after kidney transplantation, can have results that can shed more light on the issue (19). We have clearly confirmed in our set that the deficit of vitamin D with average value during the monitored 12 months after the transplantation less than 30 $\mathrm{ng} / \mathrm{ml}$ is an independent risk factor for PTDM development. We also confirmed negative correlation of average value of vitamin D and occurrence of PTDM 12 months after the transplantation, what confirms that long-term deficit of vitamin D is a risk factor not only for diabetes mellitus type 2 but also for PTDM.

Proteinuria is known to be an independent risk factor for cardiovascular disease and mortality as well as a predictor of allograft damage and loss after kidney transplantation $(20,21)$. The prevalence of proteinuria in kidney transplant recipients varies considerably from 7.5 to $45.0 \%$, depending on the threshold used to define proteinuria (22). Proteinuria in the first week after the transplantation can be induced by hyperglycaemia with osmotic diuresis when high doses of corticosteroids are administered, or also the residual proteinuria of native kidneys can be present. However, the proteinuria and albuminuria 3-6 months after the kidney transplantation is a more important factor. Authors Roland et al proved the relationship between albuminuria $(30-300 \mathrm{mg}$ /day in a sample of 24-hour urine) and the development of PTDM. Patients with proteinuria ( $>300 \mathrm{mg} /$ day in a sample of 24-hour urine) (23, 24 ) had even higher risk of PTDM occurrence. We confirmed in our set that the average proteinuria of more than $300 \mathrm{mg} / 24$ hours (determined from 20-22 samples of 24-hour urine) is an indepen- 
dent risk factor for the PTDM development and its higher value correlates with higher occurrence of PTDM. An important information is the usage of angiotensin-converting-enzyme inhibitors - ACEI or sartans in our set. Of patients having proteinuria below $150 \mathrm{mg} / 24$ hours the ACEI or sartan was used by $15 \%$ of patients as compared to $18 \%$ of patients with average value of proteinuria higher than $150 \mathrm{mg} / 24$ hours $(\mathrm{p}=0.8955)$ and results were therefore not distorted by this treatment.

It is known that patients with CKD have low serum levels of vitamin $\mathrm{D}$ related to higher mortality and quicker progression of CKD (25). Authors de Borst et al confirmed in their review, mentioning 6 studies, the reduction of proteinuria in case paricalcitol was used in non-transplanted population with CKD (26). The VITAL study showed that treatment for 24 weeks with $2 \mu \mathrm{g}$ of paricalcitol reduced residual albuminuria in patients with type 2 diabetes mellitus and kidney disease that were being treated with stable doses of ACEIs or sartans (27).

Kanter Berga et al did not confirm the improvement of either proteinuria or albuminuria in 110 patients after the kidney transplantation in case calcidiol was used (28).

The work which deals with the effect of paricalcitol on proteinuria after kidney transplantation is carried out in a limited number only and in very small sets. A study carried out in 58 patients who were monitored for a period of 18 months while taking paricalcitol is available. The authors confirmed a significant decrease of proteinuria in the monitored set by more than $50 \%$. In addition to proteinuria, that analysis confirmed the effect of paricalcitol on significant decrease of PTH (29). We assume that it is the treatment with paricalcitol with the fall of proteinuria that affects the occurrence of PTDM. We unambiguously confirmed in our set a lower occurrence of PTDM in the set of patients treated with paricalcitol as compared to patients who did not have paricalcitol in their treatment.

The limitation of our analysis is the fact that it is a retrospective analysis where we had to exclude patients using in CKD treatment other preparations (such as calcitriol) from the monitoring, but the number of such patients was negligible $(n=3)$. We also excluded from the monitoring in evaluating the impact of treatment of the secondary hyperparathyroidism on the development of PTDM patients whose treatment substantially changed $(n=10)$. Only those patients whose treatment did not change during the 12 months after the transplantation thus remained in the set for the evaluation of the treatment of secondary hyperparathyroidism. A large benefit of the study is the homogeneity of the set from the perspective of immunosuppression where results and development of PTDM were not affected by used immunosuppression.

\section{Conclusion}

We identified in our set the deficit of vitamin $\mathrm{D}$, proteinuria of more than $300 \mathrm{mg} / 24$ hours and hyperphosphatemia at the time of transplantation as independent risk factors for the development of PTDM after the kidney transplantation. Usage of paricalcitol seems to be a protective factor probably with regard to the significant impact on proteinuria as well as significantly higher lev- els of vitamin D in patients who were treated with paricalcitol. However, to confirm our findings further especially randomized controlled studies will be required, similar as those performed with non-transplanted patients with CKD or patients with diabetes mellitus type 2 .

\section{References}

1. Jardine AG, Gaston RS, Fellstrom BC, Holdaas H. Prevention of cardiovascular disease in adult recipients of kidney transplants. The Lancet 2011; 378 (9800): 1419-1427.

2. Yates CJ, Fourlanosa S, Hjelmesæth J, Colmana PG, Cohneyb SJ. New-Onset Diabetes After Kidney Transplantation - Changes and Challenges. Amer J Transplant 2012; 12: 820-828.

3. Valderhaug T, Hjelmesæeth J, Hartmann A et al. The associationof early post-transplant glucose levels with long-term mortality. Diabetologia $2011 ; 54: 1341-1349$.

4. Dedinská I, Laca L, Miklušica J, Galajda P, Mokáň M. TwelveMonth and Five-Year Analyses of Risk Factors for New-Onset Diabetes After Transplantation in a Set of Patients Homogeneous for Immunosuppression. Transplant Proc 2015; 47: 1831-1839.

5. Galassi A, Bellasi A, Papagni S et al. Which vitamin D in CKD-MBD? The time of burning questions. Biomed Res Int 2013; 2013: 864012.

6. Vaidya A, Williams JS: Vitamin D and insulin sensitivity: can gene association and pharmacogenetic studies of the vitamin D receptor provide clarity? Metabolism 2012; 61: 759-761.

7. Gonzalez-Parra E, Rojas-Rivera J, Tuñón J et al. Vitamin D receptor activation and cardiovascular disease. Nephrol Dial Transplant 2012; 27 (Suppl 4): iv17-iv21.

8. Afzal S, Bojesen SE, Nordestgaard BG. Low 25-hydroxyvitamin D and risk of type 2 diabetes: a prospective cohort study and metaanalysis. Clin Chem 2013; 59: 381-391.

9. Holick MF. Vitamin D deficiency. N Engl J Med 2007; 357: 266-281.

10. Thacher TD, Clarke BL. Vitamin D insufficiency. Mayo Clin Proc 2011; 86: 50-60.

11. Knoll GA. Proteinuria in Kidney Transplant Recipients: Prevalence, Prognosis, and Evidence-Based Management. Am J Kidney Dis 2009; 54: 1131-1144.

12. Trillini M, Cortinovis M, Ruggenenti $\mathbf{P}$ et al. Paricalcitol for Secondary Hyperparathyroidism in Renal Transplantation. JASN. 2014; doi: 10.1681/ASN.2013111185.

13. Song Y, Wang L, Pittas AG et al. Blood 25-hydroxy vitamin D levels and incident type 2 diabetes: a meta-analysis of prospective studies. Diabet Care. 2013; 36: 1422- 1428 .

14. Hypponen E, Power C. Vitamin D status and glucose homeostasis in the 1958 British birth cohort: the role of obesity. Diabet Care 2006; 29: 2244-2246.

15. Scragg R, Sowers M, Bell C. Serum 25-hydroxyvitamin D, diabetes, and ethnicity in the third national health and nutrition examination survey. Diabet Care 2004; 27: 2813-2818.

16. Tabesh M, Azadbakht L, Faghihimani E, Tabesh M, Esmaillzadeh A. Calcium-vitamin D co-supplementation influences circulating inflammatory biomarkers and adipocytokines in vitamin $\mathrm{D}$ insufficient diabetics: a randomized controlled clinical trial. J Clin Endocrinol Metab 2014; 12: jc20141977. 
17. George PS, Pearson ER, Witham MD. Effect of vitamin D supplementation on glycaemic control and insulin resistance: a systematic review and meta-analysis. Diabet Med 2012; 29: 142-150.

18. Seida JC, Mitri J, Colmers IN, Majumdar SR, Davidson MB, Edwards AL, Hanley DA, Pittas AG, Tjosvold L, Johnson JA. Effect of vitamin D3 supplementation on improving glucose homeostasis and preventing diabetes: a systematic review and meta-analysis. J Clin Endocrinol Metab 2014; 25: jc20142136.

19. Courbebaisse M, Alberti C, Colas S et al. VITamin D supplementation in renAL transplant recipients (VITALE): a prospective, multicentre, double-blind, randomized trial of vitamin D estimating the benefit and safety of vitamin D3treatment at a dose of 100,000 UI compared with a dose of 12,000 UI in renal transplant recipients: study protocol for a double-blind, randomized, controlled trial. Trials 2014;15:430.

20. Ibis A, Akgül A, Ozdemir N et al. Posttransplant proteinuria is associated with higher risk of cardiovascular disease and graft failure in renal transplant patients. Transplant Proc 2009; 41: 1604-1608.

21. Barnas U, Schmidt A, Haas $M$ et al. Parameters associated with chronic renal transplant failure. Nephrol Dial Transplant 1997; 12 (Suppl 2): $82-85$.

22. Yakupoglu U, Baranowska-Daca E, Rosen D et al. Post-transplant nephrotic syndrome: A comprehensive clinicopathologic study. Kidney Int 2004; 65: 2360-2370.
23. Pham PT, Pham PM, Pham SV et al. New onset diabetes after transplantation (NODAT): an over view. Diabetes Metab Syndr Obes 2011; 4 (4): 175-186.

24. Roland M, Gatault P, Al-Naijjar A et al. Early pulse pressure and lowgrade proteinuria as independent long-term risk factors for new-onset diabetes after kidney transplantation. Am J Transplant 2008; 8 (8): 1719-1728.

25. Kendrick J, Cheung AK, Kaufman JS et al. Associations of plasma 25-hydroxyvitamin D and 1,25-dihydroxyvitamin D concentrations with death and progression to maintenance dialysis in patients with advanced kidney disease. Am J Kidney Dis 2012; 60: 567-575.

26. de Borst MH, Hajhosseiny R, Tamez $\mathrm{H}$ et al. Active vitamin D treatment for reduction of residual proteinuria: a systematic review. J Am Soc Nephrol 2013; 24: 1863-1871.

27. Cheng J, Zhang W, Zhang $X$ et al. Efficacy and safety of paricalcitol therapy for chronic kidney disease: a meta-analysis. Clin J Am Soc Nephrol 2012; 7: 391-400.

28. Kanter Berga J, Crespo Albiach J, Beltran Catalan S et al. Vitamin $D$ deficiency in a renal transplant population: safe repletion with moderate doses of calcidiol. Transplant Proc 2010; 42: 2917-2920.

29. Aperic G, Palioras CH, Zervos A et al. The role of paricalcitol on proteinuria. J Renal Care 2011; 37 (2): 80-84.

Received March 16, 2018. Accepted April 5, 2018. 